\title{
ORIGINAL ARTICLE \\ Relation of depot-specific adipose inflammation to insulin resistance in human obesity
}

\author{
SJ Bigornia ${ }^{1}$, MG Farb², MM Mott ${ }^{2}$, DT Hess ${ }^{3}$, B Carmine $^{3}$, A Fiscale $^{3}$, L Joseph ${ }^{4}$, CM Apovian ${ }^{1}$ and N Gokce ${ }^{2}$
}

BACKGROUND: A low-grade state of adipose tissue inflammation associated with obesity has been linked to mechanisms of systemic metabolic dysfunction. However, the relation of clinical phenotypes to depot-specific inflammation has not been well examined in human obesity.

OBJECTIVE: To characterize the inflammatory status of subcutaneous and visceral fat depots, as assessed by tissue presence of macrophage crown-like structures (CLS) as a hallmark of chronic inflammation, and determine the relation of systemic insulin resistance to inflammatory abnormalities in subcutaneous and visceral fat.

METHODS: We collected adipose tissue simultaneously from subcutaneous and visceral (omental and mesenteric) depots in 92 obese participants (age $42 \pm 11$ years; $\mathrm{BMI} \geqslant 30 \mathrm{~kg} \mathrm{~m}^{-2}$ ) during planned bariatric surgery. Using immunohistochemistry, we categorized individuals as $\mathrm{CLS}^{+}$or $\mathrm{CLS}^{-}$based on the presence or absence, respectively, of macrophage CLS in subcutaneous $\left(\mathrm{CLS}_{\mathrm{s}}\right)$, omental $\left(\mathrm{CLS}_{\mathrm{o}}\right)$ and mesenteric $\left(\mathrm{CLS}_{\mathrm{m}}\right)$ adipose depots.

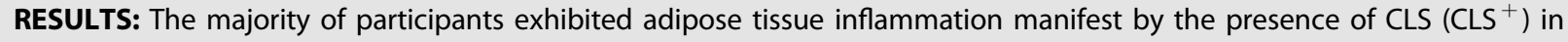
both subcutaneous and intra-abdominal visceral depots. CLS status in subcutaneous fat was highly sensitive and modestly specific for inflammation of visceral fat. In multivariable models, plasma insulin and homeostatis model assessment levels were positively associated with $\mathrm{CLS}^{+}$status in all depots independent of age, waist circumference, BMI and type 2 diabetes, and worsened with the increasing number of adipose regions involved.

CONCLUSIONS: In severely obese participants, systemic insulin resistance is linked to adipose inflammation in both subcutaneous and visceral depots. The findings suggest that examination of subcutaneous regions that are more easily accessible by transcutaneous biopsy may prove useful in clinical studies designed to investigate adipose phenotypes in relation to human disease.

Nutrition and Diabetes (2012) 2, e30; doi:10.1038/nutd.2012.3; published online 5 March 2012

Keywords: inflammation; obesity; insulin resistance

\section{INTRODUCTION}

Clinical studies consistently demonstrate a link between obesity and increased risk for developing insulin resistance ${ }^{1}$ and type 2 diabetes (T2DM). ${ }^{2}$ The most recent national data show that the majority of adults ${ }^{3}$ and a third of children in the US are overweight or obese. ${ }^{4}$ Experts now predict that 165 million Americans (at least $50 \%$ of adults) will be obese by 2030 leading to a major public health burden and cost. ${ }^{5}$ While increased adiposity is associated with metabolic and cardiovascular risks, a growing body of evidence suggests that regional adiposity with selective accumulation of intra-abdominal visceral fat may be more closely linked to disease phenotypes than subcutaneous deposition. ${ }^{6}$

A key mechanism in the pathogenesis of insulin resistance linked to obesity relates to adipose tissue inflammation that has been well demonstrated in experimental animal models and now gaining recognition in clinical human disease. ${ }^{7-9}$ Inflammatory changes in fat tissue appear to be driven by infiltration of adipose tissue macrophages that support a chronic state of inflammation strongly implicated in mechanisms of whole body metabolic dysregulation. ${ }^{10}$ We and others have shown that macrophage accumulation in subcutaneous fat in a characteristic histopathological pattern consisting of crown-like structures (CLS) is associated with altered adipose tissue gene expression, cytokine overproduction, systemic insulin resistance and vascular endothelial dysfunction in obese humans. ${ }^{10-12}$ These data support the growing paradigm that both adipose tissue quality and quantity may be relevant to disease mechanism in human obesity. Although subcutaneous fat has been more extensively studied owing to its easier access for clinical investigation, few studies have simultaneously related findings to visceral depots. ${ }^{12}$ Thus, our primary objective was to determine whether the inflammatory status of subcutaneous fat as assessed by the presence of macrophage CLS relates to the state of inflammation in visceral fat. Additionally, we sought to determine whether systemic insulin resistance relates more closely to abnormalities in subcutaneous versus visceral reserves in obese humans.

\section{SUBJECTS AND METHODS}

Participants

We consecutively enrolled obese (BMI $\geqslant 30 \mathrm{~kg} \mathrm{~m}^{-2}$ ) adult men and women, age $\geqslant 18$ years scheduled for gastric bypass surgery at the Boston Medical Center. The patient population was specifically composed of subjects with severe long-standing obesity. Preoperative dietary regimens

${ }^{1}$ Department of Medicine, Section of Endocrinology, Diabetes and Nutrition, Boston University School of Medicine, Boston, MA, USA; ${ }^{2}$ Evans Department of Medicine and Whitaker Cardiovascular Institute, Boston University School of Medicine, Boston, MA, USA; ${ }^{3}$ Department of General Surgery, Boston University School of Medicine, Boston, MA, USA and ${ }^{4}$ Section of Pathology, Boston University School of Medicine, Boston, MA, USA. Correspondence: Dr N Gokce, Evans Department of Medicine and Whitaker Cardiovascular Institute, Boston University School of Medicine, Boston Medical Center, 88 East Newton Street, D-8, Cardiology, Boston, MA 02118, USA.

E-mail: Noyan.Gokce@bmc.org

Received 13 January 2012; accepted 22 January 2012 
were uniform for all subjects, consisting of a high fiber, low fat plan with approximate daily calorie intake of $1200-1500 \mathrm{kcal}$ for women and $1500-1800 \mathrm{kcal}$ for men. ${ }^{13}$ Participants with unstable medical conditions such as active coronary syndromes, congestive heart failure, systemic infection, malignancy or pregnancy were excluded. Individuals with a medical diagnosis of type 1 diabetes were also excluded. Written informed consent was obtained from all participants. Study approval was granted by the Boston University Medical Center Institutional Review Board.

\section{Adipose tissue collection and immunohistochemistry}

In 92 obese individuals, approximately $1 \mathrm{~cm}$ pieces of adipose tissue were collected intra-operatively from three separate depots (subcutaneous, omental and mesenteric) by the surgeon during the initial stages of planned gastric bypass surgery. Biopsies were secured from regions deemed medically safe by the operating surgeon based on personal experience and were uniformly the same for each patient. Visceral fat was secured from the free edges of the greater omentum and the mesenteric appendices epiploicae of the transverse colon. The subcutaneous fat removed intraoperatively represented the same anatomic layer that would be accessed by a transcutaneous biopsy procedure lateral to the umbilicus. All the tissue samples were immediately stored in formalin or promptly frozen in liquid nitrogen to be stored at $-80^{\circ} \mathrm{C}$. Each participant provided a single biopsy specimen from each depot for analysis. Immunohistochemical stains were performed in the Department of Anatomic Pathology at the Boston Medical Center as previously described. ${ }^{11}$ Infiltration of macrophage cell populations into adipose tissue was characterized using cell-specific stains targeted to CD68 (predilute antibodies from DakoCytomation Corporation, Glostrup, Denmark). All samples were evaluated by a single pathologist (LJ) blinded to all clinical data. CLS status was assessed after examination of all fields available per slide at high-power field (HPF) magnification using light microscopy. A CLS was defined as $\mathrm{CD}^{+} 8^{+}$macrophage aggregates comprising at least $50 \%$ of the circumference circularly surrounding necrotic adipocytes. Subcutaneous, omental and mesenteric fat depots from each participant were dichotomously categorized based on the presence $\left(\mathrm{CLS}^{+}\right)$or absence $\left(\mathrm{CLS}^{-}\right)$of $\mathrm{CLS}$ in fat. In additional analyses, $\mathrm{CLS}^{+}$depots were characterized as low density (1 CLS per HPF) or high density ( $\geqslant 2$ CLS per HPF). An illustration of two adjacent macrophage CLS (high-density CLS) is displayed in Figure 1. Participants were further categorized by depotspecific CLS status in subcutaneous $\left(\mathrm{CLS}_{\mathrm{s}}\right)$ and omental fat depots $\left(\mathrm{CLS}_{\mathrm{o}}\right)$ as follows: (1) $\mathrm{CLS}^{-}$in all depots, (2) $\mathrm{CLS}_{s}^{+}$and $\mathrm{CLS}_{\mathrm{o}}^{-}$and (3) $\mathrm{CLS}_{s}^{+}$and $\mathrm{CLS}_{0}^{+}$. The data were similarly analyzed based on $\mathrm{CLS}_{\mathrm{s}}$ and $\mathrm{CLS}_{\mathrm{m}}$ (mesenteric) status.
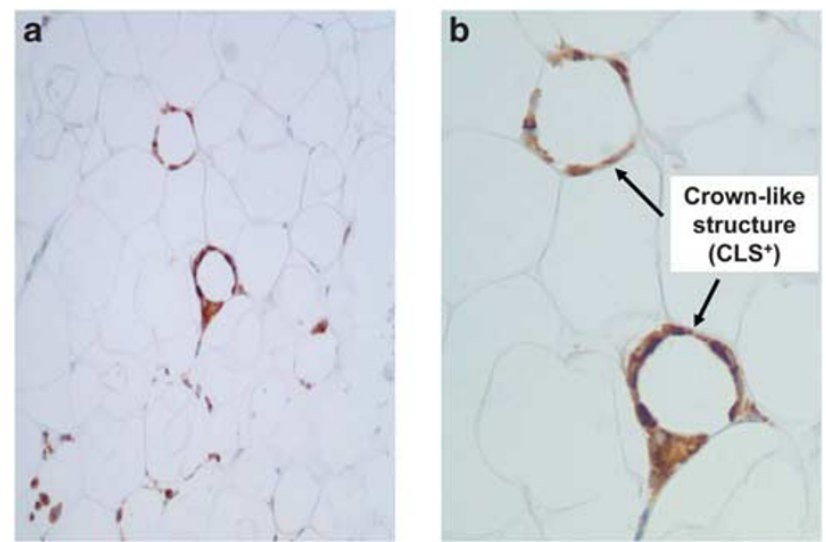

Figure 1. Representative histological illustration of inflamed adipose tissue as demonstrated by light microscopy. CD68 ${ }^{+}$macrophages (brown color) are organized into two separate 'crown-like structures' (indicated by arrows) surrounding individual adipocytes. (a) $\times 20$ Power; (b) $\times 40$ Power.

\section{Anthropometric and metabolic measures}

During a single outpatient visit before planned bariatric surgery, weight, height and $\mathrm{BMI}$ were recorded for each participant by trained personnel. Weight was obtained using a calibrated scale (Ohaus, Pine Brook, NJ, USA). Waist circumference was measured at the midpoint between the lowest rib and top of the iliac crest. All biochemical analyses were performed by the Boston Medical Center clinical chemistry laboratory, quantified from blood samples collected in a fasted state. Measured variables included plasma glucose, insulin, glycated hemoglobin A1c, total cholesterol, LDL-cholesterol, HDL-cholesterol, triglycerides and high-sensitivity C-reactive protein. Homeostatis model assessment (HOMA) was used as the index of insulin sensitivity. ${ }^{14}$

\section{Statistical analyses}

Histograms and normal $\mathrm{Q}-\mathrm{Q}$ plots were inspected to determine if continuous variables were normally distributed. Several clinical variables were not normally distributed (cholesterol, glucose, HbA1c, BMl, highsensitivity CRP, insulin and HOMA) and were natural logarithm transformed accordingly. Data are presented as mean \pm s.d. for normally distributed data or median with inter-quartile range for skewed data. We calculated sensitivity, specificity, positive predictive (PPV) and negative predictive value (NPV) of $\mathrm{CLS}_{s} \pm$ status for determining visceral $\mathrm{CLS}_{0}$ and $\mathrm{CLS}_{\mathrm{m}} \pm$ categorization. We examined whether $\mathrm{CLS}_{\mathrm{s}}, \mathrm{CLS}_{\mathrm{o}}$ and $\mathrm{CLS}_{\mathrm{m}}$ status were associated with markers of insulin resistance and glycemic parameters (that is, natural log transformed HOMA, insulin, glucose and $\mathrm{HbA1c}$ ) in separate multivariable models using analysis of covariance (ANCOVA). Waist circumference and BMI were strongly correlated $(r=0.85, P<0.0001$ by Pearson's correlation). To avoid colinearity, waist circumference was regressed onto BMI and the residuals used (WCR). Models were adjusted for age, WCR, BMI and T2DM status. Owing to the small number of male participants (14\%), we chose to not adjust for sex. However, analyses were repeated in women only and results remained similar to total cohort analyses. Next, we determined whether insulin resistance was associated with both subcutaneous and omental CLS status by ANCOVA with models adjusted as described above. Paired comparisons between $\mathrm{CLS}_{\mathrm{s}} \mathrm{CLS}_{\mathrm{o}}$ and $\mathrm{CLS}_{\mathrm{m}}$ groups were conducted by Tukey's post hoc tests. Analyses were repeated using both subcutaneous and mesenteric CLS status.

\section{RESULTS}

The clinical characteristics of all 92 participants (age $42 \pm 11$ years) that participated in the study are displayed in Table 1 . The majority of individuals were women (86\%) with longstanding class III obesity (BMI $\geqslant 40 \mathrm{~kg} \mathrm{~m}^{-2}, 78 \%$ ). Most participants exhibited evidence of impaired insulin sensitivity (HOMA $>2.0,72 \%)$ and over a third had T2DM. For the group as a whole, the prevalence of $\mathrm{CLS}^{+}$was highest in the subcutaneous depot and lowest in the omental region. Few men were $\mathrm{CLS}_{\mathrm{s}}^{-}(n=0), \mathrm{CLS}_{\mathrm{o}}^{-}(n=2)$ or $\mathrm{CLS}_{\mathrm{m}}^{-}$ $(n=1)$. The sensitivity of $\mathrm{CLS}_{\mathrm{s}}$ for $\mathrm{CLS}_{\mathrm{o}}$ and $\mathrm{CLS}_{\mathrm{m}}$ status was high (94\% and $95 \%$, respectively) with modest specificity $(43 \%$ and $57 \%$, respectively). The PPV and NPV of $\mathrm{CLS}_{\mathrm{S}}$ for $\mathrm{CLS}_{\mathrm{O}}$ status were $68 \%$ and $85 \%$, respectively, and for $\mathrm{CLS}_{\mathrm{m}}$ values were $85 \%$ for both PPV and NPV.

We explored whether $\mathrm{CLS}_{s}^{+}, \mathrm{CLS}_{\circ}^{+}$and $\mathrm{CLS}_{\mathrm{m}}^{+}$was associated with markers of insulin resistance and glycemic parameters (HOMA, insulin, glucose and $\mathrm{HbA} 1 \mathrm{c}$ ) in multivariable models adjusted for age, WCR, BMI and T2DM. As shown in Figure 2a-d, $\mathrm{CLS}_{\mathrm{s}}^{+}$was associated with increased HOMA $(P=0.01)$ and insulin $(P=0.02)$ but not glucose $(P=0.71)$ or HbA1c $(P=0.69)$. The same relationships were evident in the mesenteric depot, where $\mathrm{CLS}_{\mathrm{m}}^{+}$ was associated with increased HOMA $(P=0.05)$ and insulin $(P=0.04)$ but not glucose $(P=0.60)$ or HbA1c $(P=0.83)$. Similarly, $\mathrm{CLS}_{0}^{+}$was associated with higher HOMA $(P=0.02)$, insulin $(P=0.02)$ and positively trended for $\operatorname{HbA1c}(P=0.08)$; while glucose was not different between groups $(P=0.80)$. When participants without T2DM were analyzed separately $(n=56)$, 
Table 1. Clinical characteristics

\begin{tabular}{|c|c|c|c|}
\hline & \multicolumn{3}{|c|}{$n=92$} \\
\hline Age, years & \multicolumn{3}{|c|}{$42 \pm 11$} \\
\hline Female/male, $n$ (\%) & \multicolumn{3}{|c|}{$79(86) / 13(14)$} \\
\hline $\mathrm{BMI}, \mathrm{kg} \mathrm{m}^{-2}$ & \multicolumn{3}{|c|}{$44(10)$} \\
\hline $\mathrm{BMI} \geqslant 40 \mathrm{~kg} \mathrm{~m}^{-2}, n(\%)$ & \multicolumn{3}{|c|}{$72(78.3)$} \\
\hline Waist circumference, $\mathrm{cm}$ & \multicolumn{3}{|c|}{$113 \pm 7.2$} \\
\hline Glucose, $\mathrm{mg} \mathrm{dl}^{-1}$ & \multicolumn{3}{|c|}{$97.0(25.5)$} \\
\hline Insulin, ulU ml ${ }^{-1}$ & \multicolumn{3}{|c|}{$12.0(11.0)$} \\
\hline HOMA-IR & \multicolumn{3}{|c|}{$3.1(3.0)$} \\
\hline $\mathrm{HgA} 1 \mathrm{c}, \%$ & \multicolumn{3}{|c|}{$5.8(1.3)$} \\
\hline Total cholesterol, $\mathrm{mg} \mathrm{dl}^{-1}$ & \multicolumn{3}{|c|}{$179(45)$} \\
\hline LDL cholesterol, $\mathrm{mg} \mathrm{dl}^{-1}$ & \multicolumn{3}{|c|}{$115 \pm 33$} \\
\hline $\mathrm{HDL}$ cholesterol, $\mathrm{mg} \mathrm{dl}^{-1}$ & \multicolumn{3}{|c|}{$47 \pm 12$} \\
\hline Triglycerides, $\mathrm{mg} \mathrm{dl}^{-1}$ & \multicolumn{3}{|c|}{$118 \pm 61$} \\
\hline Hs-CRP, $\mathrm{mg} \mathrm{dl}^{-1}$ & \multicolumn{3}{|c|}{$4.9(6.8)$} \\
\hline Type 2 diabetic, $n$ (\%) & \multicolumn{3}{|c|}{$36(39)$} \\
\hline Metformin use, $n$ (\%) & \multicolumn{3}{|c|}{$32(35)$} \\
\hline Sulfonylurea use, $n(\%)$ & \multicolumn{3}{|c|}{$10(11)$} \\
\hline Thiazolidinedione use, $n$ (\%) & \multicolumn{3}{|c|}{$8(9)$} \\
\hline Insulin use, $n(\%)$ & \multicolumn{3}{|c|}{$6(7)$} \\
\hline $\begin{array}{l}\text { Adipose crown-like structure+, } \\
n(\%)\end{array}$ & Total & Female & Male \\
\hline Subcutaneous & $72(78.3)$ & $59(74.7)$ & $13(100)$ \\
\hline Omentum & $52(56.6)$ & $41(51.9)$ & $11(84.6)$ \\
\hline Mesentery & $62(67.4)$ & $50(63.3)$ & $12(92.3)$ \\
\hline $\begin{array}{l}\text { Abbreviations: BMI, body mass } \\
\text { HOMA-IR, homeostatis model a } \\
\text { sensitivity C-reactive protein. Da } \\
\text { (inter-quartile range) or proport }\end{array}$ & $\begin{array}{l}a \text { are pres } \\
\text { on, } n(\%) .\end{array}$ & $\begin{array}{l}\text {, glycated hemo } \\
\text { sulin resistance; } \\
\text { ted as mean } \pm \text { s }\end{array}$ & $\begin{array}{l}\text { lobin A1c; } \\
\text { s-CRP, high- } \\
\text { l. or median }\end{array}$ \\
\hline
\end{tabular}

the findings were directionally similar but reached statistical significance $(P<0.05)$ only for the subcutaneous depot (data not shown). There were no hypoglycemic medication-specific effects on CLS status for each depot. Waist circumference remained a significant predictor of HOMA and insulin in all models. Analyses repeated after excluding male participants $(n=13)$ did not alter the results. We performed additional analyses based on CLS density in adipose tissue. As shown in Table 2 , a minority $<20 \%$ of adipose depots exhibited high-density CLS ( $\geqslant 2 / \mathrm{HPF})$ as illustrated in Figure 1. There were no significant differences in glucose, insulin or HOMA in subjects with low as compared to high CLS density in any adipose depot.

Additionally, we investigated the relation of HOMA to adipose inflammation in analyses combining subcutaneous and omental fat tissue CLS status, adjusted for age, WCR, $\mathrm{BMI}$ and T2DM. Among all participants, 17, 23 and 49 subjects

Table 2. CLS density by adipose tissue depot

\begin{tabular}{llll}
\hline Depot & \multicolumn{3}{c}{ CLS categorization } \\
\cline { 2 - 4 } & None (0) & \multicolumn{1}{c}{$\begin{array}{c}\text { 1/HPF } \\
\text { (low density) }\end{array}$} & $\begin{array}{c}\geqslant 2 / H P F \\
\text { (high density) }\end{array}$ \\
\hline Subcutaneous & $20(21.7)$ & $56(60.8)$ & $16(17.4)$ \\
Omental & $40(43.5)$ & $49(53.3)$ & $3(3.3)$ \\
Mesentery & $30(32.6)$ & $55(59.8)$ & $7(7.6)$ \\
\hline
\end{tabular}

Abbreviations: CLS, crown-like structure; HPF, high-power field. Data are presented as $n(\%)$.
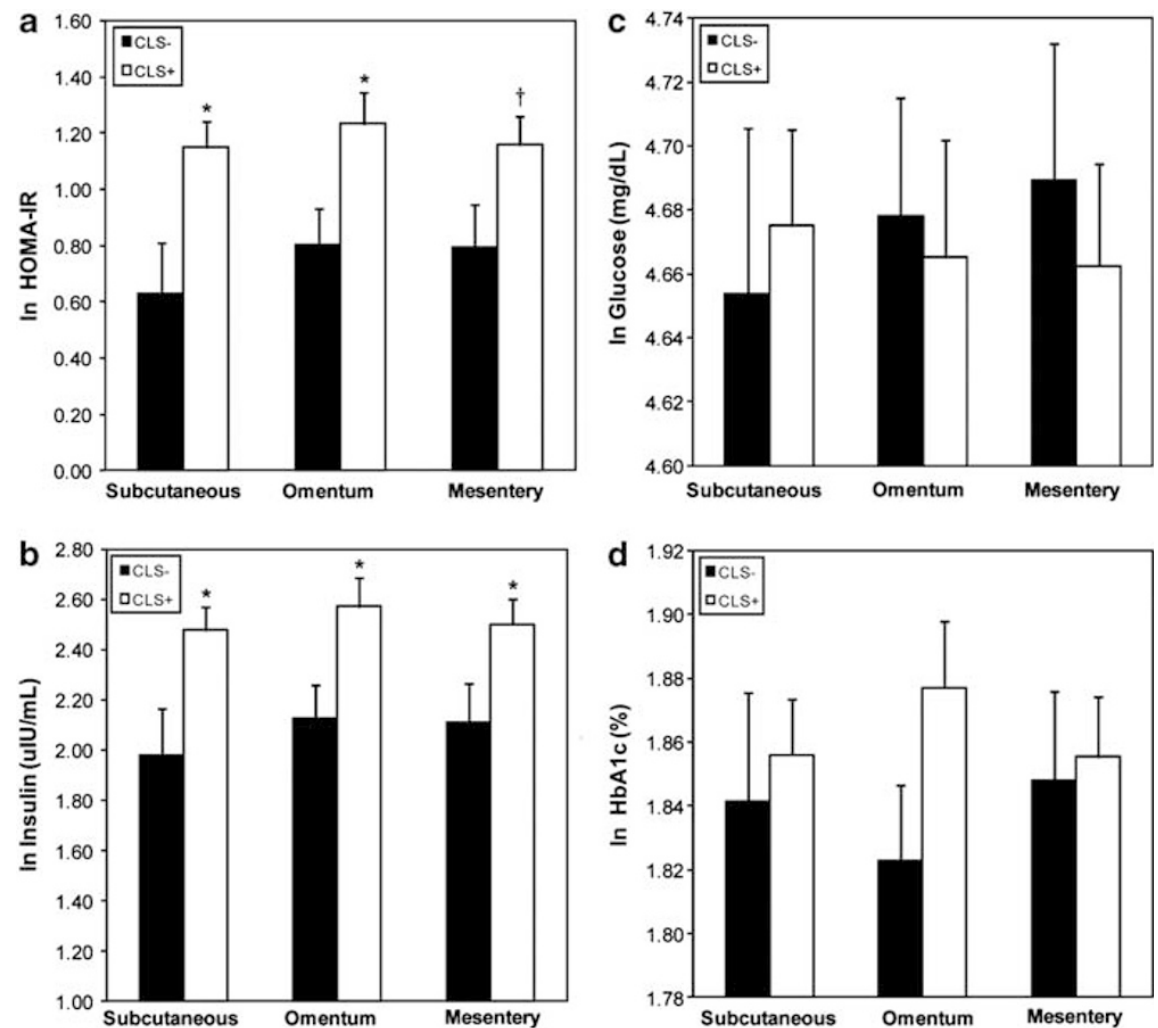

Figure 2. (a-d) Relation of subcutaneous, omental and mesenteric adipose tissue crown-like structures (CLS) status to plasma (a) HOMA (b) insulin (c) glucose and (d) HbA1c. Data are adjusted for age, WCR, BMl and prevalent T2DM. Data are presented as means \pm s.e., ${ }^{*} P<0.05$ or ${ }^{\dagger} P=0.05$ for $\mathrm{CLS}^{+}$vs $\mathrm{CLS}^{-}$within each specific depot. In = natural logarithm. 

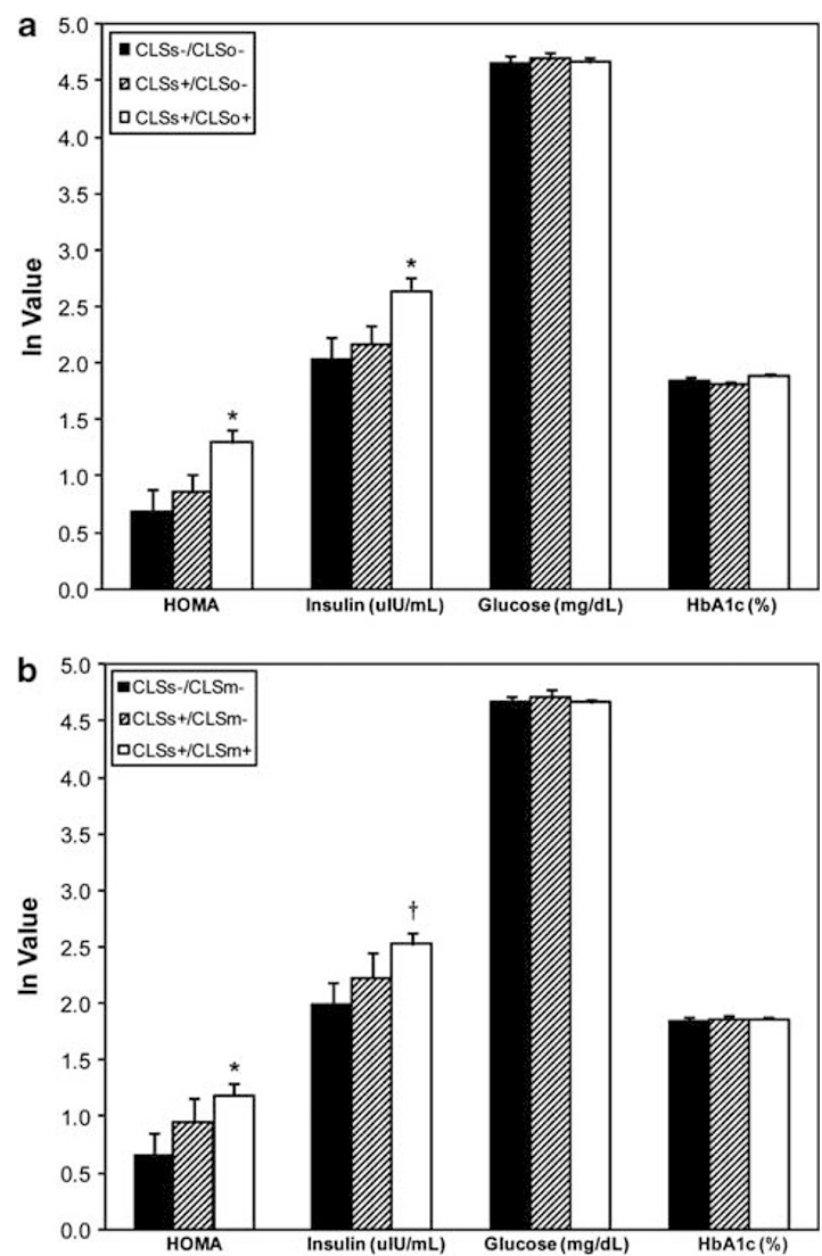

Figure 3. (a, b) Relation of plasma measures of insulin resistance and glycemic parameters to adipose inflammation by combined analyses of (a) subcutaneous-omental and (b) subcutaneousmesenteric CLS status. Data are adjusted for age, WCR, BMI and prevalent T2DM. Data are presented as mean \pm s.e., ${ }^{*} P<0.05$ or ${ }^{+} P=0.05$ for comparisons with the $\mathrm{CLS}_{\mathrm{s}}^{-} / \mathrm{CLS}_{\mathrm{o}}^{-}$or $\mathrm{CLS}_{\mathrm{s}}^{-} / \mathrm{CLS}_{\mathrm{m}}^{-}$groups. In = natural logarithm.

were $\mathrm{CLS}_{\mathrm{s}}^{-} / \mathrm{CLS}_{\mathrm{o}}^{-}, \mathrm{CLS}_{\mathrm{s}}^{+} / \mathrm{CLS}_{\mathrm{o}}^{-}$and $\mathrm{CLS}_{\mathrm{s}}^{+} / \mathrm{CLS}_{\mathrm{o}}^{+}$, respectively. Only three participants were $\mathrm{CLS}_{\mathrm{s}}^{-} / \mathrm{CLS}_{\mathrm{o}}^{+}$and were excluded from these sets of analyses, which did not affect the results. As shown in Figure 3a, HOMA and insulin increased in a graded pattern, with the $\mathrm{CLS}_{\mathrm{s}}^{-} / \mathrm{CLS}_{\mathrm{o}}^{-}$group demonstrating the lowest and $\mathrm{CLS}_{\mathrm{s}}^{+} / \mathrm{CLS}_{\mathrm{O}}^{+}$group exhibiting the highest HOMA and insulin values $(P<0.05)$. Analyses were repeated using data from mesenteric depots, and 17, 13 and 59 participants were $\mathrm{CLS}_{\mathrm{s}}^{-} / \mathrm{CLS}_{\mathrm{m}}^{-}, \mathrm{CLS}_{\mathrm{s}}^{+} / \mathrm{CLS}_{\mathrm{m}}^{-}$and $\mathrm{CLS}_{\mathrm{s}}^{+} / \mathrm{CLS}_{\mathrm{m}}^{+}$, respectively. Owing to small numbers $(n=3), \mathrm{CLS}_{\mathrm{s}}^{-} / \mathrm{CLS}_{\mathrm{m}}^{+}$were excluded from analysis. Similar to the omental depot analyses, HOMA and insulin increased across groups with increasing degrees of depot-specific inflammation as shown in Figure $3 \mathrm{~b}$. Again, waist circumference remained a significant predictor of HOMA and insulin in all models. Excluding men $(n=13)$ from the analyses did not alter the results.

\section{DISCUSSION}

In this study of severely obese individuals undergoing gastric bypass surgery, we demonstrated that the majority of participants exhibited evidence of adipose tissue inflammation as manifest by the presence of macrophage $\mathrm{CLS}\left(\mathrm{CLS}^{+}\right)$in both subcutaneous and intra-abdominal visceral (omental and mesenteric) depots.

$\mathrm{CLS}^{+}$status in subcutaneous fat was strongly associated with $\mathrm{CLS}^{+}$in each visceral depot with high sensitivity $(\geqslant 94 \%)$ and modest specificity. Increased HOMA and insulin levels were independently linked to inflammatory activation in all depots and worsened in a graded fashion with increasing number of adipose regions involved. These findings suggest that whole body metabolic dysfunction is linked to qualitative changes in several human adipose stores simultaneously. In this regard, examination of subcutaneous fat that is more easily accessible by transcutaneous biopsy may provide a window into pathophysiological alterations within deeper visceral depots.

To our knowledge this is the first human study that systematically examined the association between CLS status in subcutaneous adipose tissue (SAT) and two separate visceral adipose tissue (VAT) regions collected from both the omentum and mesentery. Our results in association with other studies using paired subcutaneous and visceral fat samples in humans ${ }^{15,16}$ and mice ${ }^{15,17,18}$ show that obesity-related macrophage accumulation occurs in multiple adipose regions. While VAT has been shown to differ in inflammatory transcriptome and secretory capacity, ascribing it a profile potentially more pathogenic compared to SAT, studies have largely been in experimental animal models and in vitro conditions. ${ }^{19-22}$ Recent clinical data in fact show that the progression from the lean to obese state is associated with largely parallel alterations in metabolic and immunoregulatory gene expression profiles in both VAT and SAT that correlate with both fat mass and measures of insulin sensitivity. ${ }^{23}$ While visceral fat mass is regarded as an important determinant of cardiometabolic risk, evidence from the Framingham Heart Study suggests that both subcutaneous and visceral loads relate to atherogenic biomarkers. ${ }^{24,25}$ Our findings are in line with several other clinical studies showing a clear association between inflammation in SAT and systemic insulin resistance. ${ }^{10-12,26,27}$ Additionally, we provide novel data by demonstrating concordant inflammatory abnormalities as defined by CLS status in VAT and SAT in human obesity. Considering the high degree of difficulty in securing visceral fat samples from human participants, our findings suggest that inflammation in SAT may serve as a reasonable proxy of inflammatory status in VAT, lending support to the notion that significant clinical information may well be learned by qualitative analysis of SAT in relation to systemic disease. ${ }^{11,12,26-30}$

Numerous experimental studies in mice show that adipose tissue inflammation driven by infiltration of proinflammatory macrophage populations is mechanistically linked to the development of insulin resistance. ${ }^{31,32} \mathrm{~A}$ direct role of adipose immune activation in impaired insulin metabolism in humans is also growing recognition. Adipose macrophage density ${ }^{11,33}$ and adipose mRNA CD68 expression ${ }^{34}$ correlate with insulin resistance and impaired glucose tolerance that decrease with weight loss. ${ }^{35}$ Adipose tissue macrophages express cytokines such as TNF- $\alpha$ and interleukins that have direct roles in mediating insulin resistance. ${ }^{9,12,36}$ In particular, accumulation of macrophages in patterns of CLS aggregating around necrotic adipocytes ${ }^{15}$ as a sign of chronic tissue inflammation is associated with diseased clinical phenotypes, including metabolic dysfunction and proatherosclerotic vascular abnormalities manifest as impaired endothelial function. ${ }^{11,37}$ Our prior work has demonstrated that inflammatory activation of adipose stores is much more heterogeneous than in animal models, as obese individuals with reduced inflammation display favorable cardiometabolic profiles that are polarized toward a lean phenotype, despite their significant excess fat burden. ${ }^{11,37,38}$ Although the temporal relationship of depotspecific inflammation in the initial stages of weight gain are unknown, we demonstrate that both SAT and VAT exhibit histopathological abnormalities that are linked to insulin resistance in advanced human obesity.

Novel to this study, we demonstrated that individuals with subcutaneous-visceral 'double positives' $\left(\mathrm{CLS}_{\mathrm{s}}^{+}\right.$and $\left.\mathrm{CLS}_{\mathrm{o}}^{+} / \mathrm{CLS}_{\mathrm{m}}^{+}\right)$, 
regardless of visceral depot sampled, had higher HOMA and plasma insulin compared with the 'double negatives' $\left(\mathrm{CLS}_{\mathrm{s}}^{-}\right.$and $\mathrm{CLS}_{\mathrm{o}}^{-} / \mathrm{CLS}_{\mathrm{m}}^{-}$). Mixed phenotypes of $\mathrm{CLS}_{\mathrm{s}}^{+}$and $\mathrm{CLS}_{\mathrm{o}}^{-} / \mathrm{CLS}_{\mathrm{m}}^{-}$displayed intermediate values, suggesting that both depots likely incrementally contribute to mechanisms of insulin resistance. We found no difference in plasma $\mathrm{HbA1c}$ and glucose between the various CLS groups, likely due to treatment-bias effects of hypoglycemic agents in diabetic participants. Our overall findings were directionally similar but relatively underpowered when individuals with diabetes were excluded from the analyses. We demonstrated that waist circumference remained a significant independent predictor of HOMA and insulin after adjustment for potential confounders including age, BMI and CLS status, supporting the notion that several different factors relating to adipose tissue quality, quantity and regional distribution are all relevant to shaping clinical disease phenotypes. ${ }^{37,39,40}$

Our present study has several limitations. We relied on a single biopsy site from each depot to minimize the surgical bleeding risk from multiple biopsies, thus it remains plausible that multi-site sampling could have reduced the number of false negatives from a specific region. Moreover, we did not observe a statistically significant relation between CLS density and insulin resistance likely owing to the low number $(<20 \%)$ of individuals that exhibited abundant tissue CLS based on our classification scheme. However, these limitations are counterbalanced by the relatively large sample size allowing for multivariate analyses in this invasive human study that examined paired samples from two distinct visceral depots, unlike any prior clinical study. We used HOMA as our index variable but acknowledge that it represents an approximation of systemic insulin resistance. ${ }^{14}$ Euglycemic clamp studies may provide more robust relationships but in our opinion are difficult to perform in such severely obese individuals. We were not able to quantify degree of visceral fat burden using imaging such as CT/MRI as most of our severely obese cohort does not fit into standard imaging machines owing to size constraints. We acknowledge that in lower weight categories, insulin-resistant individuals may exhibit higher visceral fat loads compared with the insulin-sensitive populations. We phenotyped adipose tissue based on macrophage CLS status but understand that this represents only a limited aspect of complex immunoregulatory and functional alterations that develop in adipose reserves in association with weight excess. Lastly, owing to the small number of male participants, we were unable to perform sex-specific analyses. However, our female predominance reflects the general bariatric practice nationally and sex differences in populations that seek weight loss intervention. ${ }^{41}$

\section{CONCLUSION}

In severely obese participants undergoing bariatric surgery, systemic insulin resistance was linked to adipose tissue inflammation in both subcutaneous and visceral depots. Sensitivity of adipose inflammation assessed by the presence of macrophage CLS in SAT for VAT was high ( $\geqslant 94 \%)$. The findings suggest that subcutaneous inflammatory status may serve as a reasonable indicator of inflammation in visceral depots and that both depots appear to contribute to systemic insulin resistance. We speculate that much can be learned from studying subcutaneous fat that is easily accessible by transcutaneous biopsy, thus permitting serial examination of treatment interventions designed to modulate adipose tissue phenotypes in human clinical studies.

\section{CONFLICT OF INTEREST}

Dr Apovian has served on the advisory boards for Allergan, Amylin, Orexigen, Merck, Johnson and Johnson, Arena, and Sanofi-Aventis, and has received research funding from Lilly, Amylin, Pfizer, Sanofi-Aventis, Orexigen, MetaProteomics, and the Dr Robert C and Veronica Atkins Foundation. The remaining authors declare no conflict of interest.

\section{ACKNOWLEDGEMENTS}

Dr Gokce is supported by National Institutes of Health (NIH) Grants R01 HL084213 and P01 HL081587. Dr Farb is supported by NIH Grant T32 HL07224.

\section{REFERENCES}

1 Samuel VT, Petersen KF, Shulman GI. Lipid-induced insulin resistance: unravelling the mechanism. Lancet 2010; 375: 2267-2277.

2 Guh DP, Zhang W, Bansback N, Amarsi Z, Birmingham CL, Anis AH. The incidence of co-morbidities related to obesity and overweight: a systematic review and meta-analysis. BMC Public Health 2009; 9: 88.

3 Flegal KM, Carroll MD, Ogden CL, Curtin LR. Prevalence and trends in obesity among US adults, 1999-2008. JAMA 2010; 303: 235-241.

4 Ogden CL, Carroll MD, Curtin LR, Lamb MM, Flegal KM. Prevalence of high body mass index in US children and adolescents, 2007-2008. JAMA 2010; 303: 242-249.

5 Wang YC, McPherson K, Marsh T, Gortmaker SL, Brown M. Health and economic burden of the projected obesity trends in the USA and the UK. Lancet 2011; 378: $815-825$.

6 Mathieu P, Poirier P, Pibarot P, Lemieux I, Despres JP. Visceral obesity: the link among inflammation, hypertension, and cardiovascular disease. Hypertension 2009; 53: 577-584.

7 Compher C, Badellino KO. Obesity and inflammation: lessons from bariatric surgery. JPEN J Parenter Enteral Nutr 2008; 32: 645-647.

8 Fuentes L, Roszer T, Ricote M. Inflammatory mediators and insulin resistance in obesity: role of nuclear receptor signaling in macrophages. Mediators Inflamm 2010; 2010: 219583.

9 Shoelson SE, Lee J, Goldfine AB. Inflammation and insulin resistance. J Clin Invest 2006; 116: $1793-1801$

10 Bremer AA, Devaraj S, Afify A, Jialal I. Adipose tissue dysregulation in patients with metabolic syndrome. J Clin Endocrinol Metab 2011; 96: E1782-E1788.

11 Apovian CM, Bigornia S, Mott M, Meyers MR, Ulloor J, Gagua M et al. Adipose macrophage infiltration is associated with insulin resistance and vascular endothelial dysfunction in obese subjects. Arterioscler Thromb Vasc Biol 2008; 28: $1654-1659$.

12 Wentworth JM, Naselli G, Brown WA, Doyle L, Phipson B, Smyth GK et al. Proinflammatory $C D 11 c+C D 206+$ adipose tissue macrophages are associated with insulin resistance in human obesity. Diabetes 2010; 59: 1648-1656.

13 Anderson WA, Greene GW, Forse RA, Apovian CM, Istfan NW. Weight loss and health outcomes in African Americans and whites after gastric bypass surgery. Obesity (Silver Spring) 2007; 15: $1455-1463$.

14 Matthews DR, Hosker JP, Rudenski AS, Naylor BA, Treacher DF, Turner RC. Homeostasis model assessment: insulin resistance and beta-cell function from fasting plasma glucose and insulin concentrations in man. Diabetologia 1985; 28: $412-419$.

15 Cinti S, Mitchell G, Barbatelli G, Murano I, Ceresi E, Faloia E et al. Adipocyte death defines macrophage localization and function in adipose tissue of obese mice and humans. J Lipid Res 2005; 46: 2347-2355.

16 Harman-Boehm I, Bluher M, Redel H, Sion-Vardy N, Ovadia S, Avinoach E et al. Macrophage infiltration into omental versus subcutaneous fat across different populations: effect of regional adiposity and the comorbidities of obesity. J Clin Endocrinol Metab 2007; 92: 2240-2247.

17 Alkhouri N, Gornicka A, Berk MP, Thapaliya S, Dixon LJ, Kashyap S et al. Adipocyte apoptosis, a link between obesity, insulin resistance, and hepatic steatosis. J Biol Chem 2009; 285: 3428-3438.

18 Murano I, Barbatelli G, Parisani V, Latini C, Muzzonigro G, Castellucci M et al. Dead adipocytes, detected as crown-like structures, are prevalent in visceral fat depots of genetically obese mice. J Lipid Res 2008; 49: 1562-1568.

19 Hocking SL, Chisholm DJ, James DE. Studies of regional adipose transplantation reveal a unique and beneficial interaction between subcutaneous adipose tissue and the intra-abdominal compartment. Diabetologia 2008; 51: 900-902.

20 Palou M, Priego T, Sanchez J, Rodriguez AM, Palou A, Pico C. Gene expression patterns in visceral and subcutaneous adipose depots in rats are linked to their morphologic features. Cell Physiol Biochem 2009; 24: 547-556.

21 Rytka JM, Wueest S, Schoenle EJ, Konrad D. The portal theory supported by venous drainage-selective fat transplantation. Diabetes 2010; 60: 56-63.

22 Yu R, Kim CS, Kwon BS, Kawada T. Mesenteric adipose tissue-derived monocyte chemoattractant protein-1 plays a crucial role in adipose tissue macrophage migration and activation in obese mice. Obesity (Silver Spring) 2006; 14: $1353-1362$.

23 Klimcakova E, Roussel B, Marquez-Quinones A, Kovacova Z, Kovacikova M, Combes $M$ et al. Worsening of obesity and metabolic status yields similar molecular adaptations in human subcutaneous and visceral adipose tissue: decreased metabolism and increased immune response. J Clin Endocrinol Metab 2011; 96: E73-E82. 
24 Fox CS, Massaro JM, Hoffmann U, Pou KM, Maurovich-Horvat P, Liu CY et al. Abdominal visceral and subcutaneous adipose tissue compartments: association with metabolic risk factors in the Framingham Heart Study. Circulation 2007; 116 $39-48$.

25 Pou KM, Massaro JM, Hoffmann U, Vasan RS, Maurovich-Horvat P, Larson MG et al. Visceral and subcutaneous adipose tissue volumes are cross-sectionally related to markers of inflammation and oxidative stress: the Framingham Heart Study. Circulation 2007; 116: 1234 - 1241.

26 Evans J, Goedecke JH, Soderstrom I, Buren J, Alvehus M, Blomquist C et al. Depot- and ethnic-specific differences in the relationship between adipose tissue inflammation and insulin sensitivity. Clin Endocrinol (Oxf) 2011; 74: $51-59$.

27 Klimcakova E, Roussel B, Kovacova Z, Kovacikova M, Siklova-Vitkova M, Combes M et al. Macrophage gene expression is related to obesity and the metabolic syndrome in human subcutaneous fat as well as in visceral fat. Diabetologia $2011_{\text {; }}$ 54: $876-887$.

28 Aron-Wisnewsky J, Tordjman J, Poitou C, Darakhshan F, Hugol D, Basdevant A et al. Human adipose tissue macrophages: $\mathrm{m} 1$ and $\mathrm{m} 2$ cell surface markers in subcutaneous and omental depots and after weight loss. J Clin Endocrinol Metab 2009; 94: 4619-4623.

29 McLaughlin TM, Liu T, Yee G, Abbasi F, Lamendola C, Reaven GM et al. Pioglitazone increases the proportion of small cells in human abdominal subcutaneous adipose tissue. Obesity (Silver Spring) 2010; 18: 926-931.

30 Mutch DM, Pers TH, Temanni MR, Pelloux V, Marquez-Quinones A, Holst C et al. A distinct adipose tissue gene expression response to caloric restriction predicts 6-mo weight maintenance in obese subjects. Am J Clin Nutr 2011; 94 1399- 1409.

31 Arkan MC, Hevener AL, Greten FR, Maeda S, Li ZW, Long JM et al. IKK-beta links inflammation to obesity-induced insulin resistance. Nat Med 2005; 11: $191-198$.

32 Xu H, Barnes GT, Yang Q, Tan G, Yang D, Chou CJ et al. Chronic inflammation in fat plays a crucial role in the development of obesity-related insulin resistance. J Clin Invest 2003; 112: $1821-1830$.
33 Cancello R, Tordjman J, Poitou C, Guilhem G, Bouillot JL, Hugol D et al. Increased infiltration of macrophages in omental adipose tissue is associated with marked hepatic lesions in morbid human obesity. Diabetes 2006; 55: 1554-1561.

34 Di Gregorio GB, Yao-Borengasser A, Rasouli N, Varma V, Lu T, Miles LM et al. Expression of CD68 and macrophage chemoattractant protein-1 genes in human adipose and muscle tissues: association with cytokine expression, insulin resistance, and reduction by pioglitazone. Diabetes 2005; 54: $2305-2313$.

35 Cancello R, Henegar C, Viguerie N, Taleb S, Poitou C, Rouault C et al. Reduction of macrophage infiltration and chemoattractant gene expression changes in white adipose tissue of morbidly obese subjects after surgery-induced weight loss. Diabetes 2005; 54: 2277-2286.

36 Gregor MF, Hotamisligil GS. Inflammatory mechanisms in obesity. Annu Rev Immunol 2011; 29: 415-445.

37 Farb MG, Bigornia S, Mott M, Tanriverdi K, Morin KM, Freedman JE et al. Reduced adipose tissue inflammation represents an intermediate cardiometabolic phenotype in obesity. J Am Coll Cardiol 2011; 58: 232-237.

38 Ouchi N, Higuchi A, Ohashi K, Oshima Y, Gokce N, Shibata R et al. Sfrp5 is an anti-inflammatory adipokine that modulates metabolic dysfunction in obesity. Science 2010; 329: 454-457.

39 Kim JY, van de Wall E, Laplante M, Azzara A, Trujillo ME, Hofmann SM et al. Obesity-associated improvements in metabolic profile through expansion of adipose tissue. J Clin Invest 2007; 117: $2621-2637$.

40 Kloting N, Fasshauer M, Dietrich A, Kovacs P, Schon MR, Kern M et al. Insulinsensitive obesity. Am J Physiol Endocrinol Metab 2010; 299: E506-E515.

41 Buchwald $\mathrm{H}$, Avidor $\mathrm{Y}$, Braunwald $\mathrm{E}$, Jensen MD, Pories W, Fahrbach $\mathrm{K}$ et al. Bariatric surgery: a systematic review and meta-analysis. JAMA 2004; 292: $1724-1737$.

This work is licensed under the Creative Commons AttributionNonCommercial-No Derivative Works 3.0 Unported License. To view a copy of this license, visit http://creativecommons.org/licenses/by-nc-nd/3.0/ 